Piguet, P.F., Grau, G.E. \& Vassalli, P. (1990), Subcutaneous perfusion of tumor necrosis factor induces local proliferation of fibroblasts, capillaries, and epidermal cells, or massive tissue necrosis. Am. J. Pathol., $136,103-110$.

Piguet, P.F., Grau, G.E., Allet, B. \& Vassalli, P. (1987), Tumor necrosis factor is an effector of skin and gut lesions of the acute phase of graft-versus-host disease. J. Exp. Med., 166, 1280-1289.

Rothstein, J.L. \& Schreiber, H. (1988), Synergy between tumor necrosis factor and bacterial products causes hemorrhagic necrosis and lethal shock in normal mice. Proc. nat. Acad. Sci. (Wash.), 85, 607-611.

Rubin, B.Y. (1992), TNF and viruses: multiple interrelationships, in "Tumor necrosis factor, structure, function and mechanism of action" (Aggarwal, B.B. \& Vilcek, J.) (pp. 331-340). Marcel Dekker, New York.

Spriggs, D.R., Imamura, K., Rodriguez, C., Sariban, E. \& Kufe, D.W. (1988), Tumor necrosis factor expres- sion in human epithelial tumor cell lines. J. Clin. Invest., $81,455-460$.

Streilein, J.W. \& Bergstresser, P.R. (1988), Genetic basis of ultraviolet-B effects on contact hypersensitivity. Immunogenetics, 27, 252-258.

Trefzer, U., Brockhaus, M., Loetscher, H., Parlow, F., Kapp, A., Schopf, E. \& Krutmann, J. (1991), 55-kd tumor necrosis factor receptor is expressed by human keratinocytes and plays a pivotal role in regulation of human keratinocyte ICAM-1 expression. J. Invest Dermatol., 97, 911-916.

Vassalli, P., Grau, G.E. \& Piguet, P.F. (1992), TNF in autoimmune diseases, Graft versus host reactions and pulmonary fibrosis, in "Tumor necrosis factor: structure, function and mechanism of action" (Vilcek, J., Aggarwal, B.B.) (pp. 409-430). Marcel Dekker, New York.

Yoshikawa, T. \& Streilein, J.W. (1990), Tumor necrosis alpha and ultraviolet $B$ light have similar effects on contact sensitivity in mice. Reg. Iminunol., 3, 139-144.

\title{
Lung and gut injury induced by tumour necrosis factor
}

\author{
D.G. Remick \\ M2210 Medical Science I, 1301 Catherine Road, Department of Pathology, University of Michigan, \\ Ann Arbor, MI 48109-0602 (USA)
}

\section{Tumour-necrosis-factor-induced acute pulmonary injury}

\section{A) Exogenous $T N F$}

Several investigators have injected purified, recombinant TNF into experimental animals and observed pulmonary injury. One of the first reports was by Tracey et al. (1986) who injected recombinant human TNF (rhTNF) into rats. High doses $(1.8 \mathrm{mg} / \mathrm{kg}$ body weight) were used, and the rats developed a constellation of signs and pathologic findings which were similar to those observed in septic shock. Multiple organs were affected, including the lungs which showed inflammation and haemorrhage. This group also demonstrated that $0.1 \mathrm{mg} / \mathrm{kg}$ of rhTNF administered by intra-arterial infusion would induce multiple haemorrhagic pulmonary lesions (Tracey et al., 1987). In another study, acute lung injury was also observed $3.5 \mathrm{~h}$ after injection of rhTNF into rats (Chang et al., 1989). These investigators were not able to inhibit the lung injury with a platelet- activating factor antagonist, in contrast to findings with the small intestine as described below. A state similar to adult respiratory distress syndrome was induced in rats by giving $4 \times 10^{5}$ units of TNF per $\mathrm{kg}$ per $\mathrm{h}$ for $24 \mathrm{~h}$ (Ferrari-Baliviera et al., 1989). The rats developed significant alterations in the static compliance of the lungs, as well as an increase in the weight of the lungs. Histologic examination disclosed focal, intermittent inflammation. Gaskill has also reported that continuous infusion of rhTNF at $100 \mu \mathrm{g} / \mathrm{kg} /$ day causes a significant increase in the wet weight of the lungs (Gaskill, 1988). Mice have been used as experimental animals and 500,000 units $/ \mathrm{kg}$ of rhTNF will induce microthrombi in the lungs, but very little actual tissue damage (Talmadge et al., 1987). We also were not able to document significant lung injury in mice after intravenous injection of $10 \mu \mathrm{g}$ of rhTNF into mice (Remick et al., 1987), although there were substantial lesions in the intestines (described below). At the dose of $100 \mu \mathrm{g}$, there was evidence of pulmonary injury (Remick and Kunkel, in press). 
Other animals have been injected with rhTNF and the pathology documented; in particular, guinea pigs have also been used as experimental animal models for TNF-induced acute lung injury. Injection of rhTNF at $1 \times 10^{6}$ units $/ \mathrm{kg}$ caused lung injury, as measured by increases in albumin leakage and lung water (Stephens et al., 1988a). There were also more neutrophils per alveolus after TNF treatment. Treatment with pentoxifylline (Lilly et al., 1989) or depletion of neutrophils (Stephens et al., 1988b) would prevent the lung injury induced by TNF. It should be noted that prevention of lung injury in the face of decreased numbers of neutrophils is controversial. Neutropenic patients may still develop adult respiratory distress syndrome (Maunder et al., 1986; Ognibene et al., 1986). Additionally, TNF-induced lung injury in sheep $(12 \mu \mathrm{g} / \mathrm{kg})$ is not attenuated by prior depletion of neutrophils (Horvath et al., 1988). The differences in these studies may relate to the different species of animals that were used (guinea pig vs. sheep), the dose of TNF that was administered, or the method used to neutrophil-deplete the animals.

Two other species that have been used to investigate the toxicity of TNF are dogs and rabbits, and in both species TNF will cause lung injury. In dogs, $60 \mu \mathrm{g} / \mathrm{kg}$ of rhINF were shown to cause early derangements of oxygenation, as measured by sophisticated physiologic parameters (Eichacker et al., 1991). In rabbits, $1 \mu \mathrm{g} / \mathrm{kg}$ will cause "hepatization" of the lung, with neutrophils and red blood cells in the alveolus (Okusawa et al., 1988).

The previous work has given recombinant TNF systemically, and at much higher doses than would be observed after the induction of septic shock. In many cases, local production of cytokines may be critical, and the toxicity of aerosolized TNF has been specifically examined. Debs et al. (1988) instilled $2 \mathrm{mg} / \mathrm{rat}$ of rhTNF into the lungs, and margination of neutrophils was observed 1 day later, followed by pulmonary haemorrhage. Ulich et al. (1991) instilled less TNF (5,000 units/rat) and observed a marked influx of neutrophils into the lung which peaked $24 \mathrm{~h}$ after exposure. Taken together, these studies indicate that TNF will induce lung injury, whether it is given locally or injected intravenously.

We have also closely examined the pulmonary pathology observed after injection of TNF. For our studies, we prepared recombinant murine TNF. The isolated protein migrated as a single band on SDSpolyacrylamide gel electrophoresis, reacted with an antibody directed against murine TNF (Chensue et $a l ., 1988)$ and induced cytotoxicity of TNF-sensitive target cells. Endotoxin was less than $0.3 \mathrm{pg} / \mu \mathrm{g}$ of recombinant material. The rmTNF was diluted in normal saline with $0.05 \%$ bovine serum albumin as a carrier and was then injected intravenously. Two sets of controls were done: i) $\mathrm{TNF}$ was heatinactivated by boiling for $2 \mathrm{~h}$ and ii) vehicle alone which contained the equivalent amount of endotoxin found in the recombinant protein. Mice were evaluated $4 \mathrm{~h}$ after intravenous injection. The degree of neutrophilic infiltrate was quantitated biochemically by measuring the myeloperoxidase content of the lung (Remick et al., 1990). The rmTNF induced a profound neutrophil sequestration within the lung (fig. 1). This was not due to contaminating endotoxin, since heat inactivation, or injection of vehicle with the same amount of endotoxin, did not induce similar changes. It has previously been reported that endotoxin will synergize with TNF to induce toxicity (Ozaki, Oyama, and Kume, 1989; Rothstein and Schreiber, 1988); however, nanogram quantities of endotoxin were needed and our preparation contained only 3 picograms.

\section{B) Endogenous TNF}

The previous section dealt exclusively with the documentation of lung injury observed after exposure to injected TNF and these studies provide important, specific information about the toxic effects of TNF. However, all of the studies are inherently flawed, since they do not completely replicate the complex interactions that occur during an inflamma-

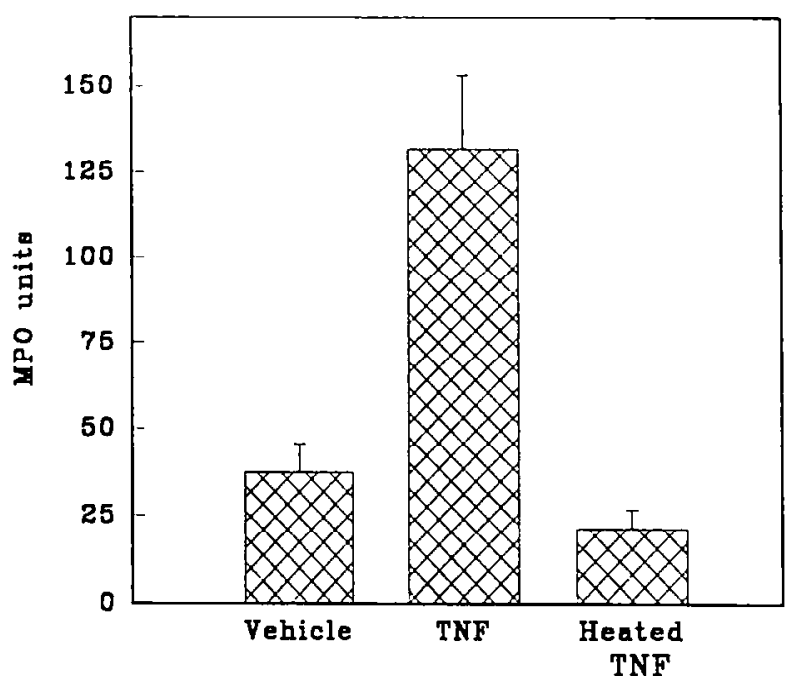

Fig. 1. Effects of rmTNF on lungs.

Ten $\mu \mathrm{g}$ of $\mathrm{rmTNF}$ were injected intravenously and the lungs harvested $4 \mathrm{~h}$ later and processed for myeloperoxidase activity (MPO). The TNF induced substantial recruitment of neutrophils to the lung. Vehicle indicates the vehicle alone which contained the same amount of contaminating endotoxin as the rmTNF preparation ( 3 picograms). Heated TNF was heat-inactivated prior to injection. The rmTNF induced significantly more pulmonary MPO than either of these 2 controls. ( $p<05$ by Student-Newman-Keuls). 
tory response. This is particularly important for cytokines, where early alarm cytokines such as TNF and IL1 will induce the synthesis of later cytokines (DeForge et al., 1992). Cytokines will also synergize with each other to induce organ injury, as has been documented for the interactions between TNF and ILl (Okusawa et al., 1988; Waage and Espevik, 1988). To complete the story of TNF-induced lung injury, it is necessary to look at experimental animals with lung injury and determine if TNF is present. If TNF can be found, then blocking with an antibody should provide protection against the injury. Table I lists several experimental models of acute lung injury where TNF has been implicated as a causative agent. This is not meant to be an exhaustive listing, but is provided mostly to show the wide range of disease processes that are believed to mediatcd by TNF.

No current discussion of the toxicity of TNF would be complete without mentioning the protective role of TNF. Upregulation of TNF gene expression is a normal physiologic response to infections, and blunting TNF may actually allow enhanced growth of organisms. This was directly shown in pulmonary infections induced by Legionella pneumophila, where treatment with TNF would augment the ability of mice to clear a pulmonary infection (Blanchard et al., 1988). Further work by Nelson et al. (1991) has shown that acute ethanol ingestion decreases the production of TNF in lung lavage fluid and increases the number of bacteria (Klebsiella pneumoniae) in the lung. Multiple other studies have shown that addition of anti-TNF antibodies will reduce the hosts' ability to clear an infectious challenge (Eskandari et al., 1992 ; Echtenacher et al., 1990; Havell, 1989). As with many aspects of inflammation, the proper balance must be maintained between the pro-inflammatory, beneficial effects of TNF and the organ-damaging potential of the cytokine.

\section{TNF-induced chronic pulmonary damage}

TNF has also been implicated as a mediator of chronic pulmonary injury. The bleomycin model of pulmonary fibrosis has been used successfully to study the pathogenesis and progression of pulmonary fibrosis. Investigators have shown that bleomycin will directly stimulate production of TNF (Scheule $e t a l$, 1992; Micallef et al., 1991; Everson and Chandler, 1992). The role of TNF has been most extensively studied by Piguet and associates (1989). They instilled bleomycin intratracheally and found evidence for mRNA coding for TNF 5 to 15 days later. They were a!so able to inhibit the progression of pulmonary fibrosis by treatment with an anti-TNF antibody.

Pulmonary fibrosis may also be initiated by silica particles, and alveolar cells will respond to silica by producing TNF (Bissonnette and RolaPleszczynski, 1989). Piguet and associates have also investigated this model and demonstrated that addition of exogenous TNF will accclcratc silica-induced pulmonary fibrosis (Piguet et al., 1990). Further proof of the importance of TNF was provided by antibody blocking experiments.

\section{TNF-induced intestinal damage}

There is less published data on the effects of TNF on the intestinal tract. Tracey's original work documented damage to the intestinal tract, although several organs were also affected (Tracey et al., 1986). Other investigators have also found intestinal injury after injection of recombinant human TNF which consisted of diarrhoea (Gaskill, 1988), apoptotic cells in the mucosa of the duodenum (Talmadge et al., 1987) or haemorrhagic necrosis of the caecum (Chang et al., 1989). Interestingly, Ozaki, Oyama, and Kume found pathologic changes in rats restricted to the in-

Table I. Experimental animal models associated with TNF-induced lung injury.

\begin{tabular}{lccl} 
Experimental model & $\begin{array}{c}\text { TNF } \\
\text { detected }\end{array}$ & $\begin{array}{c}\text { Anti-TNF } \\
\text { protects }\end{array}$ & \multicolumn{1}{c}{ Reference } \\
\hline LPS injection & Yes & Yes & Remick et al., 1990 \\
IgG immune complex & Yes & Yes & Warren et al., 1989 \\
Hepatic ischemia/reperfusion & Yes & Yes & Colletti et al., 1990 \\
Intestinal ischemia/reperfusion & Yes & Yes & Caty et al., 1990 \\
Aspiration pneumonia & Yes & Yes & Goldman et al., 1990 \\
\hline
\end{tabular}

For each of the models, TNF was detected either in the circulation or in the lavage fluid. All of these are models of acute lung injury, which develops within hours after initiation of damage. Lung injury was measured by different parameters, such as leukocyte sequestration, histologic damage, or increase in vascular permeability. 


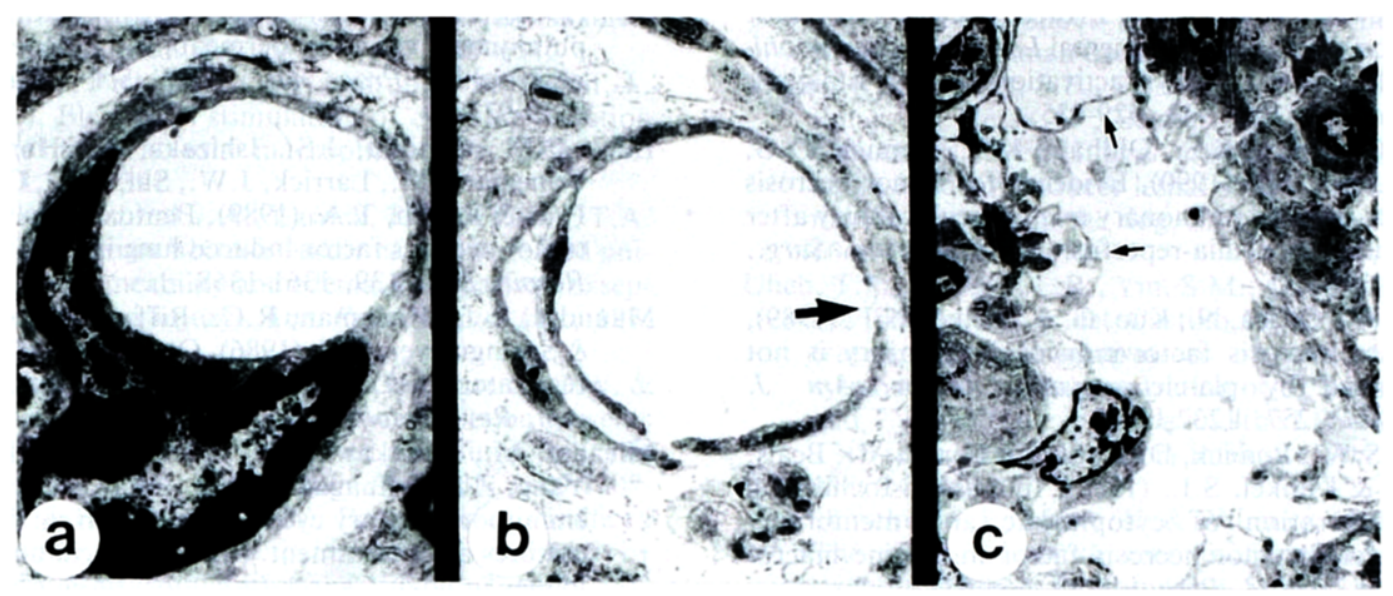

Fig. 2. Effects of rhTNF on endothelium of the small intestine.

Ten $\mu g$ of rhTNF were injected intravenously, the animals sacrificed $2 \mathrm{~h}$ later and the vasculature of the small intestine examined by electron microscopy. Panel a is normal histology with an intact endothelial cell. In $b$, the endothelial cell layer has retracted leaving the basement membrane exposed (arrow). Further damage is observed in panel $c$, with marked disruption of the endothelium and blebbing of the endothelial cell membrane (arrows). Reprinted with permission, Laboratory Investigation.

testines when "pure" TNF was injected (1989). However, if there was contaminating endotoxin, then more widespread changes were observed. Attempts to define the mechanism of the bowel necrosis were made by Sun and Hsueh (1989). In their work, the necrosis induced by either LPS, recombinant TNF $(0.5 \mathrm{mg} / \mathrm{kg})$ or a combination of both agents could be blocked by a platelet-activating factor receptor antagonist.

The physiologic effects of TNF were closely examined by the infusion of $5.7 \times 10^{4}$ units $/ \mathrm{kg} / \mathrm{h}$ for $6 \mathrm{~h}$ in dogs (van Lanschot, Mealy, and Wilmore, 1990). There was a decrease in intestinal blood flow despite fluid resuscitation. Upon completion of the study, 6 of 7 dogs had infarcts in the small bowel. Additional studies on the physiologic effects of rhTNF demonstrated that intravenous injection of $0.25 \mathrm{mg} / \mathrm{kg}$ induced delayed gastric emptying and increased emptying of the caecum (Patton et al., 1987). Further work by this group showed that injection of $16.5 \mathrm{mg} / \mathrm{kg}$ would induce necrosis and inflammation of the mucosa of the small bowel. The stomach and large intestine were less severely affected. The authors mention that human and muose TNF caused similar pathology.

We have also closely examined the effect of recombinant human TNF in rodents and have shown that the intestines are the most severely injured organs (Remick et al., 1987). Intravenous injection of $10 \mu \mathrm{g} / \mathrm{mouse}(0.45 \mathrm{mg} / \mathrm{kg})$ induced watery diarrhoea within $2 \mathrm{~h}$. There was evidence of increased vascular permeability in the small bowel at $1 \mu \mathrm{g} /$ mouse. No other organs showed evidence of vascular permeability at this dose, including the lungs. Ultrastructural examination of the small bowel showed necrosis of the tips of the villi. There was severe damage to the endothelial cells. This consisted of swelling of the endothelial cells of the small bowel with exposed basement membranes (fig. 2). Since there was also evidence of shock (increased haematocrit), we postulated that much of the intestinal mucosal injury may have been due to poor perfusion. In this setting of decreased blood flow, the damage to the endothelium would be particularly significant since it would exacerbate the decreased availability of oxygen and nutrients to the intestine.

The weight of experimental evidence favours a role for TNF in lung injury. The data using anti-TNF antibodies to inhibit experimental animal models is compelling. The role of TNF in intestinal injury is less clear, and further work will be needed to clarify the issue. In particular, antibody inhibition studies are needed.

\section{References}

Bissonnette, E. \& Rola-Pleszczynski, M. (1989), Pulmonary inflammation and fibrosis in a murine model of asbestosis and silicosis. Possible role of tumor necrosis factor. Inflammation, 13, 329-339. 
Blanchard, D.K., Djeu, J.Y., Klein, T.W., Friedman, II. \& Stewart, W.E. (1988), Protective effects of tumor necrosis factor in experimental Legionella pneumophila infections of mice via activation of PMN function. J. Leukoc. Biol., 43, 429-435.

Caty, M.G., Guicc, K.S., Oldham, K.T., Remick, D.G. \& Kunkel, S.I. (1990), Evidence for tumor necrosis factor-induced pulmonary microvascular injury after intestinal ischemia-reperfusion injury. Ann. Surg., 212, 694-700.

Chang, S.W., Ohara, N., Kuo, G. \& Voelkel, N.F. (1989), Tumor necrosis factor-induced lung injury is not mediated by platelet-activating factor. $A \mathrm{~m} . J$. Physiol., 257, L232-L239.

Chensue, S.W., Remick, D.G., Shmyr Forsch, C., Beals, T.F. \& Kunkel, S.L. (1988), Immunohistochemical demonstration of cytoplasmic and membraneassociated tumor necrosis factor in murine macrophages. Am. J. Pathol., 133, 564-572.

Colletti, L.M., Remick, D.G., Burtch, G.D., Kunkel, S.L., Strieter, R.M. \& Campbell, D.A., Jr. (1990), Role of tumor necrosis factor-alpha in the pathophysiologic alterations after hepatic ischemia/reperfusion injury in the rat. J. Clin. Invest., 85, 1936-1943.

Debs, R.J., Fuchs, H.J., Philip, R., Montgomery, A.B., Brunette, E.N., Liggitt, D., Patton, J.S. \& Shellito, J.E. (1988), Lung-specific delivery of cytokines induces sustained pulmonary and systemic immunomodulation in rats. J. Immunol., 140, 3482-3488.

DeForge, L.E., Kenney, J.S., Jones, M.L., Warren, J.S. \& Remick, D.G. (1992), Biphasic production of IL-8 in lipopolysaccharide (LPS)-stimulated human whole blood. Separation of LPS- and cytokine-stimulated components using anti-tumor necrosis factor and antiIL-1 antibodies. J. Imınunol., 148, 2133-2141.

Eichacker, P.Q., Hoffman, W.D., Farese, A., Banks, S.M., Kuo, G.C., MacVittie, T.J. \& Natanson, C. (1991), TNF but not IL-1 in dogs causes lethal lung injury and multiple organ dysfunction similar to human sepsis. J. Appl. Physiol., 71, 1979-1989.

Eskandari, M.K., Bolgos, G., Miller, C., Nguyen, D.T., DeForge, L.E. \& Remick, D.G. (1992), Anti-tumor necrosis factor antibody therapy fails to prevent lethality after cecal ligation and puncture or endotoxemia. J. Immunol., 148, 2724-2730.

Everson, M.P. \& Chandler, D.B. (1992), Changes in distribution, morphology, and tumor necrosis factoralpha secretion of alveolar macrophage subpopulations during the development of bleomycin-induced pulmonary fibrosis. Am. J. Path., 140, 503-512.

Ferrari-Baliviera, E., Mealy, K., Smith, R.J. \& Wilmore, D.W. (1989), Tumor necrosis factor induces adult respiratory distress syndrome in rats. Arch. Surg., $124,1400-1405$.

Gaskill, H.V. (1988), Continuous infusion of tumor necrosis factor: mechanisms of toxicity in the rat. J. Surg. Res., 44, 664-671.

Goldman, G., Welbourn, R., Kobzik, L., Valeri, C.R., Shepro, D. \& Hechtman, H.B. (1990), Tumor necrosis factor-alpha mediates acid aspiration-induced systemic organ injury. Ann. Surg., 212, 513-9; discuss.

Havell, E.A. (1989), Evidence that tumor necrosis factor has an important role in antibacterial resistance. J. Immunol., 143, 2894-2899.
Horvath, C.J., Ferro, T.J., Jesmok, G. \& Malik, A.B. (1988), Recombinant tumor necrosis factor increases pulmonary vascular permeability independent of neutrophils. Proc. nat. Acad. Sci. (Wash.), 85, 9219-9223.

Lilly, C.M., Sandhu, J.S., Ishizaka, A., Harada, H., Yonemaru, M., Larrick, J.W., Shi, T.X., O'Hanley, P.T. \& Raffin, T.A. (1989), Pentoxifylline prevents tumor necrosis factor-induced lung injury. Am. Rev. Respir. Dis., 139, 1361-1368.

Maunder, R.J., Hackman, R.C., Riff, E., Albert, R.K. \& Springmeyer, S.C. (1986), Occurrence of the adult respiratory distress syndrome in neutropenic patients. Am. Rev. Respir. Dis., 133, 313-316.

Micallef, M., Hosokawa, M., Shibata, T., Nakane, A., Yang, Z.B., Minagawa, T. \& Kobayashi, H. (1991), Immunoregulatory cytokine release in rat spleen cell cultures after treatment with bleomycin and its analogues in vivo. Cancer Immunol. Immunother., 33 , 33-38.

Nelson, S., Bagby, G., Andresen, J., Nakamura, C., Shellito, J. \& Summer, W. (1991), The effects of ethanol, tumor necrosis factor, and granulocyte colonystimulating factor on lung antibacterial defenses. $A d v$. Exp. Med. Biol., 288, 245-253.

Ognibene, F.P., Martin, S.E., Parker, M.M., Schlesinger, T., Roach, P., Burch, C., Shelhamer, J.H. \& Parrillo, J.E. (1986), Adult respiratory distress syndrome in patients with severe neutropenia. New Engl. J. Med., 315, 547-551.

Okusawa, S., Gelfand, J.A., Ikejima, T., Connolly, R.J. \& Dinarello, C.A. (1988), Interleukin 1 induces a shock-like state in rabbits. Synergism with tumor necrosis factor and the effect of cyclooxygenase inhibition. J. Clin. Invest., 81, 1162-1172.

Ozaki, Y., Oyama, T. \& Kume, S. (1989), Exacerbation of toxic effects by endotoxin contamination of recombinant human tumor necrosis factor. Cancer Chemother. Pharmacol., 23, 231-237.

Patton, J.S., Peters, P.M., McCabe, J., Crase, D., Hansen, S., Chen, A.B. \& Liggitt, D. (1987), Development of partial tolerance to the gastrointestinal effects of high doses of recombinant tumor necrosis factoralpha in rodents. J. Clin. Invest., 80, 1587-1596.

Piguet, P.F., Collart, M.A., Grau, G.E., Kapanci, Y. \& Vassalli, P. (1989), Tumor necrosis factor/cachectin plays a key role in bleomycin-induced pneumopathy and fibrosis. J. Exp. Med., 170, 655-663.

Piguet, P.F., Collart, M.A., Grau, G.E., Sappino, A.P. \& Vassalli, P. (1990), Requirement of tumour necrosis factor for development of silica-induced pulmonary fibrosis. Nature (Lond.), 344, 245-247.

Remick, D.G., Kunkel, R.G., Larrick, J.W. \& Kunkel, S.L. (1987), Acute in vivo effects of human recombinant tumor necrosis factor. Lab. Invest., 56 , 583-590.

Remick, D.G. \& Kunkel, S.L., Pathophysiologic alterations induced by tumor necrosis factor (1993), Int. Rev. Exp. Pathol., 34, 7-25.

Remick, D.G., Strieter, R.M., Eskandari, M.K., Nguyen, D.T., Genord, M.A., Raiford, C.L. \& Kunkel, S.L. (1990), Role of tumor necrosis factor-alpha in lipopolysaccharide-induced pathologic alterations. Am. J. Path., 136, 49-60.

Rothstein, J.L. \& Schreiber, H. (1988), Synergy between 
tumor necrosis factor and bacterial products causes hemorrhagic necrosis and lethal shock in normal mice. Proc. nat. Acad. Sci. (Wash.), 85, 607-611.

Scheule, R.K., Perkins, R.C., Hamilton, R. \& Holian, A. (1992), Bleomycin stimulation of cytokine secretion by the human alveolar macrophage. Am. J. Physiol., 262, L386-L391.

Stephens, K.E., Ishizaka, A., Larrick, J.W. \& Raffin, T.A. (1988a), Tumor necrosis factor causes increased pulmonary permeability and edema. Comparison to septic acute lung injury. Am. Rev. Respir. Dis., 137, 1364-1370.

Stephens, K.E., Ishizaka, A., Wu, Z.H., Larrick, J.W.\& Raflin, T.A. (1988b), Granulocyte depletion prevents tumor necrosis factor-mediated acute lung injury in guinea pigs. Am. Rev. Respir. Dis., 138, 1300-1307.

Sun, X.M. \& Hsueh, W. (1988), Bowel necrosis induced by tumor necrosis factor in rats is mediated by platelet-activating factor. J. Clin. Invest., 81, 1328-1331.

Talmadge, J.E., Bowersox, O., Tribble, H., Lee, S.H., Shepard, H.M. \& Liggitt, D. (1987), Toxicity of tumor necrosis factor is synergistic with gammainterferon and can be reduced with cyclooxygenase inhibitors. Am. J. Path., 128, 410-425.

Tracey, K.J., Beutler, B., Lowry, S.F., Merryweather, J., Wolpe, S., Milsark, I.W., Hariri, R.J., Fahey, T.J. 3d., Zentella, A., Albert, J.D., Shires, G.T. \& Cera$\mathrm{mi}$, A. (1986), Shock and tissue injury induced by recombinant human cachectin. Science, 234, 470-474.

Tracey, K.J., Lowry, S.F., Fahey, T.J. 3d., Albert, J.D., Fong, Y., Hesse, D., Beutler, B., Manogue, K.R., Calvano, S., Wei, H. et al. (1987), Cachectin/tumor necrosis factor induces lethal shock and stress hormone responses in the dog. Surg. Gynecol. Obstet., $164,415-422$.

Ulich, T.R., Watson, L.R., Yin, S.M., Guo, K.Z., Wang, P., Thang, H. \& del Castillo, J. (1991), The intratracheal administration of endotoxin and cytokines. - 1. Characterization of LPS-induced IL-1 and TNF mRNA expression and the LPS-, IL-1-, and TNF-induced inflammatory infiltrate. Am. J. Palh., 138, 1485-1496.

Van Lanschot, J.J., Mealy, K. \& Wilmore, D.W. (1990), The effects of tumor necrosis factor on intestinal structure and metabolism. Ann. Surg., 212, 663-670.

Waage, A. \& Espevik, T. (1988), Interleukin 1 potentiates the lethal effect of tumor necrosis factor alpha/cachectin in mice. J. Exp. Med., 167, 1987-1992.

Warren, J.S., Yabroff, K.R., Remick, D.G., Kunkel, S.L., Chensue, S.W., Kunkel, R.G., Johnson, K.J. \& Ward, P.A. (1989), Tumor necrosis factor participates in the pathogenesis of acute immune complex alveolitis in the rat. J. Clin. Invest., 84, 1873-1882.

\title{
TNF- $\alpha$ and insulin-dependent diabetes mellitus
}

\author{
C. Mueller (1), M.A. Imboden (1), M.W. Hess (1), J.A. Laissue (1) and C.C. Carnaud (2) \\ 1) Department of Pathology, University of Bern, 3010 Bern (Switzerland), and \\ (2) INSERM U25, Hopital Necker, 75730 Paris
}

TNF- $\alpha$ has been shown to be involved in the pathogenesis of many inflammatory diseases including cerebral malaria (Grau et al., 1987), BCG-induced granuloma formation (Kindler et al., 1989) and silicainduced pulmonary fibrosis (Piguet et al., 1990). Its pathogenctic rolc in autoimmune disease, however, is less clear (Jacob, 1992; Vassalli, 1992). In particular, studies on a potential involvement of TNF in the pathogenesis of insulin-dependent diabetes mellitus (DDM) produced controversial results so far, pointing to either a harmful or to a beneficial role of this cytokine in the destruction of $\beta$ cells: systemic administration of TNF- $\alpha$ to diabetes-prone NOD mice or BB rats delayed or even prevented the onset of IDDM (Satoh et al., 1989, 1990; Jacob et al., 1990). A decrease in the extent of insulitis was observed when TNF- $\alpha$ was administered together with interferon- $\gamma$ (Campbell et al., 1991). The observation that, upon stimulation of peritoneal macrophages from NOD mice, there was only low production of TNF- $\alpha$ led to the assumption that reduced capacity to produce TNF- $\alpha$ predisposes to IDDM. However, the fact that in diabetes-prone BB rats, elevated TNF production by activated macrophages is observed before insulitis occurs (Rothe et al., 1990), does not support such a concept. The disease-preventing effects of systemic administration of TNF- $\alpha$ in NOD mice or diabetes-prone BB rats (Satoh et al., 1989, 1990; 